\title{
In memoriam Dr. Mario Molina, 1943-2020
}

\section{In memoriam Dr. Mario Molina, 1943-2020}

\author{
Luis Molina-Fernández de Lara* \\ Unidad de electrofisiología cardiaca, Hospital General de México Dr. Eduardo Liceaga, Ciudad de México, México
}

No cabe duda de que lo que se comparte durante la infancia es determinante para el resto de la vida. Nosotros éramos siete en total, tres mujeres y cuatro hombres, que nos llevábamos muy bien: jugábamos pingpong en pijama todos los fines de semana. Recuerdo que había una columna junto a la mesa y que a veces jugábamos "con la columna», lo que hacía imposible contestarle al contrincante. Mi hermano Roberto era el más tramposo... aunque los demás no nos quedábamos atrás.

El juego que más recuerdo era el de «los esclavos»: cada uno era el esclavo durante cierto tiempo y luego se cambiaban los roles. José Mario era el mejor esclavo; no repelaba ni se quejaba. Un día en esas estábamos cuando entró mi mamá al cuarto de mis hermanos mientras Roberto le ordenaba algo al esclavo José Mario. Sorprendido por mi mamá, rápidamente se levantó de la cama para hacer jlo que le habían ordenado! Realmente José Mario siempre obedecía; yo creo que para evitarse problemas.

José Mario era bastante solitario y taciturno. A los dos mayores les encantaba la música "clásica» y a ambos les debo ese enorme placer. Mario aprendió a tocar el violín, aunque nunca con demasiada pasión. No me acuerdo de que tocara durante horas y horas. La verdad es que lo escuché pocas veces; nada del otro mundo.

Se llamaba José Mario por mi abuelo paterno, Mario, que fue alcalde del Puerto de Veracruz, y José porque nació el 19 de marzo, día del Señor San José, de quien mi papá era muy devoto.

De niños jugábamos mucho en el jardín de la casa. Mi tío Mariano (hermano de mi mamá) traía pesas y aparatos para hacer gimnasia y el más asiduo era José Mario. Era el consentido de Leonor, la cocinera. En realidad, comía de todo y por su orden, aunque nunca fue gordo.

No tenía muchos amigos. Jugaban con avioncitos de motor de gasolina y una línea que controlaba el subir y bajar del aeroplano; consistía en dar vueltas y vueltas haciéndolo subir y bajar... sin más chiste, aunque un día le pegó con el avión a un amigo suyo y le sangró la oreja. Me impresionó mucho.

De regreso de un viaje a Europa mis papás le trajeron un cochecito Schuco ${ }^{\circledR}$, que era, literalmente, lo máximo. Un rato después de los regalos y la euforia de la llegada, mi mamá pegó el grito en el cielo cuando vio el Schuco ${ }^{\circledR}$ de José Mario totalmente desbaratado. Cuando lo regañaron, él explicó que no funcionaba, y poco tiempo después (para asombro y regocijo de mi mamá) el cochecito estaba armado y ifuncionando!

Mis cuatro hermanos mayores estuvieron toda la primaria en el Colegio Fernández de Lara, que era de mi mamá y mis tías. Estudiaron la secundaria y preparatoria en la Academia Hispano Mexicana, de refugiados españoles y de altísimo nivel. Cursó la carrera en la Universidad Nacional Autónoma de México (UNAM). El día de su examen final hubo una manifestación en la

\section{Correspondence:}

*Luis Molina

E-mail: Imolina@unam.mx
Date of reception: 26-10-2020

Date of acceptance: $29-10-2020$

DOI: 10.24875/HMCM.M20000013
Available online: $18-11-2020$ Hosp Med Clin Manag. 2020;13:93-5

2604-0018 / ( 2020 Mexican Regional Hospitals of High Specialty and Federal Hospitals. Published by Permanyer. This is an open access article under the CC BY-NC-ND license (http://creativecommons.org/licenses/by-nc-nd/4.0/). 
entrada de la Facultad porque un profesor no quiso ponerle un 10. Sus compañeros estaban dispuestos al escándalo para defender al mejor alumno, no para exigir que aprobaran los flojos...

En nuestra casa había un par de salitas (la azul y la verde) que eran la interfase para llegar a los cuartos de los cuatro hombres: Roberto y José Mario en el primero, y Javier y yo hasta el fondo. Allí había un «medio baño» del que José Mario se apoderó para montar toda una serie de matraces y la parafernalia de un laboratorio de química. Al poco tiempo empezó a hacer hule-espuma en moldes metálicos, como si fueran panes muy esponjosos. Junto con Javier Lebrija (uno de sus amigos cercanos) iban a montar una fábrica y, con eso, poder cerrar la frontera a la importación. Yo estaba muy asombrado, aunque mis papás no hicieron mayor aspaviento. El final de esta «fábrica» que montaron fuera de la casa fue que su amigo se dedicó a la producción comercial y José Mario siguió en la investigación.

Cuando yo estaba en la preparatoria iba por las tardes al laboratorio de Fisiología en la Facultad de Medicina, gracias a que José Mario iba a la de Química. Nos íbamos en su Volkswagen bastante destartalado, que bautizamos como el Ypiranga, igual que el barco en que se fue Porfirio Díaz a Europa. Recuerdo bien cómo vimos el progreso de la construcción del edificio de Celanese en Av. Revolución. Platicábamos de todo, arquitectura, fisiología, la UNAM, aunque nunca me contaba sus cosas. No le conocimos ninguna novia. No era de emborracharse (nunca lo vi siquiera «subido de copas»). Su vida era solo suya.

Camino a Australia, a la primera embajada de mi papá, nos quedamos en San Francisco para visitar a mi hermano Mario cuando estaba en Berkeley. No nos dijo que no solo tenía novia, sino que ya vivían juntos. Luisa Tan, de origen chino, pero nacida en Filipinas, fue su esposa y colaboradora hasta años después del Premio Nobel. Fue un drama entre ellos porque no le otorgaron el premio a ella también. Tuvieron a Felipe, pianista y médico, que vive actualmente en Boston.

El 11 de octubre de 1995, poco después de las ocho de la mañana, me llamó por teléfono un buen amigo y, sin más preámbulo, me repitió gritando: ¡Mario Molina, Premio Nobel de Química! Al principio no entendí de qué se trataba y solo quedé un poco aturdido. Después de la tercera vez que me lo dijo, comprendí que mi hermano acababa de "ganar el gordo». Inmediatamente le hablé a su oficina en el Massachusetts Institute of Technology (MIT) en Boston, para felicitarlo y hablar con él. Me contestó la llamada más aturdido que yo, diciendo que sí, que en efecto le acababan de comunicar de la Real Academia de Ciencias de Estocolmo que le otorgaban el Premio Nobel de Química de ese año; además, ya les había hablado a algunos amigos y sí, no era broma...Estaba muy contento, aunque ya se notaba un poco nervioso por lo que le esperaba.

Inmediatamente después me comuniqué con todos mis hermanos y la euforia era total. Decidimos que, por supuesto, iríamos todos a Estocolmo a pesar de lo crítico de la situación económica. Durante todo el mes que siguió estuvimos planeando quiénes iban a ir, cuántos boletos íbamos a tener para tal o cual evento, cuántas personas podían ir a tal o cual ceremonia. En fin, fuimos doce miembros de la familia directa: hermanos, cuñadas y sobrinos, una pareja de amigos de México y tres compañeros del MIT. ¡Diecisiete en total!

Al llegar a Estocolmo nos dieron un sobre con un programa y las invitaciones para los diferentes eventos; todo estaba perfectamente programado: tipo de evento, de qué hora a qué hora, traje adecuado, sitio y hora de salida del autobús, en fin, todos los detalles. Los laureados iban acompañados del cónyuge y, algunos, de algún hijo. Al día siguiente salió en la prensa que, en efecto, todos los profesores iban con uno o dos invitados excepto Molina, que jeran diecisiete!, pero era normal porque era mexicano. Nos reímos mucho.

El primer día hubo una reunión de bienvenida para los galardonados y sus familiares, a la cual asistieron, además, los miembros de la Fundación Nobel y los que iban a ser los edecanes de los laureados, que eran altos funcionarios del Ministerio de Relaciones Exteriores. Quizá lo más impresionante de esa reunión fue darnos cuenta de que, a pesar de haber 11 ganadores del Premio Nobel (10 de ese año y el presidente de la Fundación Nobel que había ganado 12 años atrás), eran personas totalmente normales, comunes y corrientes. Familias chicas, grandes, niños, jóvenes y, todos, eufóricos, riendo de todo y tomando fotografías. Una reunión muy tranquila, muy normal. Al día siguiente hubo una conferencia de prensa de los laureados en economía, química y física; después, un cóctel y entrevistas con la prensa internacional. Por la noche nos fuimos a cenar toda la familia a un lugar típicamente sueco. 
El programa del Nobel está conformado por conferencias, entrevistas, visitas a la ciudad y sus alrededores, comidas en las embajadas, y claro, todas las actividades del "gran día", el 10 de diciembre. Todos los años es lo mismo: la llegada a Estocolmo es el 6 de diciembre, conferencias en las academias los días 7 y 8 , comida en la embajada el 9. El día 10 es el aniversario luctuoso de Alfred Nobel, y día de la entrega del premio; por la mañana, todos los premiados (y solo ellos) asisten a un ensayo general de la ceremonia. A las 3 p.m. tenemos que estar en un salón del Gran Hotel para la sesión oficial de fotografías, a las 3:15 abordamos el transporte que nos lleva al Teatro de la Ciudad (el equivalente al Palacio de Bellas Artes), en donde tenemos que estar en nuestros lugares a las 4 p.m.; a las 4:20 llegan miembros de la familia real. A las 4:30 en punto empieza la ceremonia con la entrada de todos los protagonistas. En escasos 35 minutos se acaba todo: discursos, entreactos musicales, entregas, aplausos y muchísima emoción.

De allí nos trasladamos al Palacio de la Ciudad (que sería algo así como entre el Palacio Nacional y las oficinas del Departamento del DF), en donde se lleva a cabo el «banquete Nobel» ipara 1,350 personas! En la mesa central está la familia real con los laureados y sus cónyuges. Después de la entrada, con la debida pompa y circunstancia, empiezan los brindis: primero por el rey, y luego el Rey (él mismo) brinda a la memoria de Alfred Nobel. Hay música y un espectáculo, cada año diferente, entre platillo y platillo. Al final, nos invitan a pasar a la parte superior, en donde tiene lugar el baile.

Entre un mundo de gente interesante encontré al sobrino nieto de Nobel, a quien habíamos conocido un par de días antes y con quien habíamos entablado una relación muy cordial. Ambos estábamos con nuestras esposas bailando, encantados por el ambiente; nos detuvimos a comentar el momento, tomar un descanso y brindar por la maravillosa ocasión. En eso estábamos cuando me dijo: «Bueno, Luis, ¿tú crees que el Premio
Nobel es importante?». Contesté, sin entender muy bien lo que quería decir, "Creo que es el más importante desde hace casi un siglo». «Pues bien (dijo muy serio), el Premio Nobel es importante gracias a personas como Mario...»

En una sola frase entendí que el Premio Nobel ise viste con las personas a quienes se otorga! Desgraciadamente no es un fenómeno que esté claro para muchos que creen que lo que los viste es el puesto. El Premio Nobel no es una lotería: Mario Molina no se ganó «el gordo», el Nobel se ganó a Mario Molina.

Mi hermano fue siempre taciturno y reservado. Como reminiscencia de la infancia, fue el esclavo de sus dos esposas. Hace casi dos años tuvo una depresión severa, por lo que perdió diez kilos. Como su médico, le exigí que volviera a jugar tenis y tratar de recuperar su vida.

Amante de ese deporte, José Mario murió súbitamente mientras miraba la Copa Roland Garros. Se sintió mal (sin dolor) y, echándose al sillón, le dijo a mi cuñada «me voy a desmayar" y cayó muerto. Falleció a los 77 años, en el pináculo de su vida, víctima de una arritmia cardiaca fulminante, sin haber sufrido enfermedades horribles, dejándonos en una orfandad inconmensurable.

La muerte tiene una extraña manera de elegir las fechas de su llegada: el 11 de octubre de 1988 falleció Leonor, mi hermana mayor; el 10 de diciembre de 1979 murió en un accidente de cacería Javier, mi hermano menor. A José Mario le otorgaron el Nobel precisamente un 11 de octubre (de 1995) y lo recibió un 10 de diciembre. Veinticinco años después, como una irónica jugada del destino, el mismo día en que otorgaron el Premio Nobel de Química del 2020 falleció mi hermano. Se fue un ser humano que deja un terrible hueco no solo en nuestra familia y en mis recuerdos, sino en la investigación y en la ciencia de México y del mundo. 